\title{
Influência da nutrição mineral na intensidade da mancha-de-olho-pardo em mudas de cafeeiro(1)
}

\author{
Adélia Aziz Alexandre Pozza(2), Hermínia Emília Prieto Martinez ${ }^{(3)}$, Sérgio Luiz Caixeta ${ }^{(4)}$, \\ Antônio Américo Cardoso ${ }^{(3)}$, Laércio Zambolim( ${ }^{(5)}$ e Edson Ampélio Pozza ${ }^{(6)}$
}

\begin{abstract}
Resumo - Objetivando avaliar a intensidade da mancha-de-olho-pardo do cafeeiro, variedade Catuaí Vermelho, com relação ao estado nutricional das plantas quanto a $\mathrm{N}$ e $\mathrm{K}$, realizou-se um experimento no viveiro da Universidade Federal de Viçosa, em Viçosa, MG, utilizando solução nutritiva circulante. Empregaram-se 16 tratamentos, em delineamento inteiramente casualizado, com três repetições e duas plantas por parcela, em esquema fatorial com quatro doses de $\mathrm{K}(3,5,7$ e $9 \mathrm{mmol} / \mathrm{L})$ e quatro doses de $\mathrm{N}(3,7,11$ e $15 \mathrm{mmol} / \mathrm{L})$. Após sete inoculações de conídios, e avaliações, colheram-se as plantas. A produção de matéria seca total, a área foliar total, e a área abaixo da curva de progresso (AACP) do número total de folhas não foram influenciadas pelas doses de $\mathrm{K}$, mas aumentaram com o incremento das doses de N. Observou-se elevação, na AACP, do número de lesões por folha, e na desfolha com o aumento das doses de $\mathrm{K}$ e a redução das doses de $\mathrm{N}$. A elevação nas doses de $\mathrm{K}$ promoveu redução nos teores foliares de $\mathrm{Ca}$ e $\mathrm{Cu}$. Os teores foliares de $\mathrm{P}, \mathrm{Mg}$, $\mathrm{Mn}$ e Fe não foram influenciados pelas doses de $\mathrm{K}$ e tiveram pequena redução com o aumento de $\mathrm{N}$ na solução, elevando-se a seguir.
\end{abstract}

Termos para indexação: Coffea arabica, nutrição das plantas, nutrientes minerais, Cercospora coffeicola, doenças das plantas.

\section{Influence of the mineral nutrition on intensity of brown-eye spot in young coffee plants}

\begin{abstract}
The experiment was carried out at the coffee nursery of the Universide Federal de Viçosa, in Viçosa, MG, Brazil, using nutrient circulating solution to evaluate the intensity of brown-eye spot (Cercospora coffeicola), variety Catuaí Vermelho, as a function of $\mathrm{N}$ and $\mathrm{K}$. A completely randomized design with 16 treatments, three replicates, and two plants per plot was used in a factorial with four levels of $\mathrm{K}(3,5,7$ and $9 \mathrm{mmol} / \mathrm{L})$ combined with four levels of $\mathrm{N}(3,7,11$ and $15 \mathrm{mmol} / \mathrm{L})$. After seven inoculations and evaluations, the plants were picked. Total dry matter production, total leaf area, and the area below the curve of progress (AACP) for the total number of leaves were not influenced by the levels of K, but increased with increasing levels of $\mathrm{N}$. There was increase in AACP areas for the number of lesions per leaf and defoliation, with the increase of $\mathrm{K}$ levels, and a reduction of $\mathrm{N}$ levels. The increase in $\mathrm{K}$ levels reduced the $\mathrm{Ca}$ and $\mathrm{Cu}$ leaf contents, indicating possible relation between its contents and the increase of the disease. The $\mathrm{P}, \mathrm{Mg}, \mathrm{Mn}$, and Fe leaf contents were not influenced by the $\mathrm{K}$ levels, and had a small reduction with increased $\mathrm{N}$ contents in the nutrient solution, increasing thereafter.
\end{abstract}

Index terms: Coffea arabica, plant nutrition, mineral nutrients, Cercospora coffeicola, plant diseases.

(1) Aceito para publicação em 13 de abril de 2000 .

Extraído da dissertação de mestrado, apresentada pela primeira autora à Universidade Federal de Viçosa (UFV), Viçosa, MG.

(2)EPAMIG, Caixa Postal 176, CEP 37200-000 Lavras, MG. Bolsista do Consórcio Brasileiro de Pesquisa e Desenvolvimento do Café. E-mail: adelia@ufla.br

(3)UFV, Dep. de Fitotecnia, CEP 36571-000 Viçosa, MG. E-mail: hermínia@mail.ufv.br, aacardoso@mail.ufv.br

(4)UFV, Dep. de Fitotecnia, Bolsista do CNPq.

E-mail: slcaixeta@mail.ufv.br

(5)UFV, Dep. de Fitopatologia. E-mail: zambolim@mail.ufv.br

(6)UFLA, Dep. de Fitopatologia, Caixa Postal 37, CEP 37200-000 Lavras, MG. E-mail: eapozza@ufla.br

\section{Introdução}

A cultura do cafeeiro no Brasil sempre ocupou posição de destaque, não só pela importância econômica, mas também por exercer importante função social, pois é geradora de grande número de empregos, diretos e indiretos, sendo responsável pela fixação de grande parte da população na zona rural. Considerando-se este aspecto e que novas áreas estão sendo utilizadas para a instalação de lavouras cafeeiras nas diferentes regiões do País, a produção 
de mudas livres de doenças torna-se cada vez mais importante.

Nos viveiros, a incidência do fungo é favorecida por excesso de irrigação ou por deficiência hídrica, desequilíbrio nutricional e insolação. Por conseguinte, as plantas apresentam desfolha intensa, tornando-se raquíticas e impróprias ao plantio (Fernandez-Borrero et al., 1966). Os nutrientes minerais exercem funções específicas no metabolismo vegetal, afetando, assim, seu crescimento e sua produção. Além disso, a nutrição mineral apresenta envolvimento secundário em termos das funções dos nutrientes no metabolismo vegetal, como alterações na morfologia (forma de crescimento), anatomia (paredes das células da epiderme mais grossas, lignificadas ou silificadas) e composição química (síntese de compostos tóxicos), as quais podem aumentar ou reduzir a resistência das plantas aos patógenos (Marschner, 1995).

Com a expansão da cultura cafeeira, a introdução de novas variedades e a diminuição do uso de fungicidas protetores em prol dos fungicidas sistêmicos de solo, a mancha-de-olho-pardo causada por Cercospora coffeicola Berk. \& Cooke atingiu alta intensidade, podendo reduzir de $15 \%$ a $30 \%$ a produtividade no campo, tornando-se, portanto, sério problema para a economia.

As medidas de controle conhecidas não têm sido satisfatórias. A interação patógeno/hospedeiro e sua relação causal com as perdas observadas carecem de informações seguras.

Neste trabalho, avaliou-se os efeitos da nutrição nitrogenada e potássica sobre a incidência e a severidade de $C$. coffeicola em plantas jovens de cafeeiros.

\section{Material e Métodos}

$\mathrm{O}$ experimento foi realizado no viveiro de mudas da Universidade Federal de Viçosa, em Viçosa, Minas Gerais. As sementes de café (Coffea arabica $\mathrm{L}$.), pertencentes à variedade Catuaí Vermelho LCH 2077-2-5-44, foram semeadas em bandejas de plástico, que continham areia lavada com ácido clorídrico a $10 \%$ e pH corrigido posteriormente para 5,5 a 6,5. O delineamento experimental foi inteiramente casualizado, com 16 tratamentos, três repetições e duas plantas por parcela. Cada vaso com duas plantas/vaso constituiu uma parcela. Os 16 tratamentos consistiram de um fatorial $4 \times 4$, ou seja, quatro doses de $\mathrm{K}$
(3, 5, 7 e $9 \mathrm{mmol} / \mathrm{L})$ combinadas com quatro doses de $\mathrm{N}$ $(3,7,11$ e $15 \mathrm{mmol} / \mathrm{L})$.

Sessenta dias após a semeadura, em fevereiro de 1997, as plântulas, quando se encontravam no estádio de "palito de fósforo", foram selecionadas e transplantadas para vasos de plástico pintados com tinta reflexiva. Estes vasos, com $3 \mathrm{~kg}$ de areia lavada com ácido clorídrico a $10 \%$ e pH corrigido para o mesmo $\mathrm{pH}$ da água desmineralizada, estavam conectados, por intermédio de mangueiras, a potes de plástico de drenagem, também pintados com tinta reflexiva.

As soluções nutritivas com doses crescentes de $\mathrm{N}$ e $\mathrm{K}$ foram calculadas a partir da solução de Hoagland \& Arnon (1950), e as concentrações de micronutrientes empregadas em todos os tratamentos foram $46 \mu \mathrm{mol} / \mathrm{L}$ de B, $0,3 \mu \mathrm{mol} / \mathrm{L} \mathrm{de} \mathrm{Cu}, 89,6 \mu \mathrm{mol} / \mathrm{L} \mathrm{de} \mathrm{Fe}, 12,6 \mu \mathrm{mol} / \mathrm{L}$ de $\mathrm{Mn}$, $0,1 \mu \mathrm{mol} / \mathrm{L}$ de $\mathrm{Mo}$ e $1,3 \mu \mathrm{mol} / \mathrm{L}$ de $\mathrm{Zn}$. As mudas foram irrigadas três vezes ao dia com a referida solução. Após essa irrigação, a solução nutritiva era escoada para os potes de plástico de drenagem. Nesses potes, a água evaporada durante a irrigação foi reposta com água desmineralizada, e o pH da solução, corrigido para 5,5 a 6,5. Tal procedimento foi realizado todos os dias, durante todo o período do experimento.

Este experimento teve cobertura de plástico de polietileno transparente, dois metros acima da bancada, com o objetivo de evitar o contato da água da chuva com a solução e permitir a passagem da luz solar.

Ao atingirem o estádio de "orelha-de-onça", as mudas foram infectadas com suspensão de conídios de C. coffeicola. O patógeno foi obtido tomando-se folhas infectadas no campo, lavadas em água corrente e detergente; em seguida, as folhas foram colocadas em câmara úmida, por 12 horas. Os conídios formados foram retirados da superfície foliar com pincel de ponta macia. A concentração da suspensão de conídios para as inoculações foi ajustada em câmara-de-neubaeuer para 15.000 conídios $/ \mathrm{mL}$.

Os conídios foram inoculados quinzenalmente, no período de março a julho de 1997. Após cada inoculação, as plantas foram pulverizadas com água desmineralizada, por 48 horas, para manter umidade necessária à penetração e posterior colonização.

Realizaram-se sete avaliações quinzenais, no período de 21/4/97 a 11/8/97, determinando-se o número total de folhas do hospedeiro, o número de folhas com lesões de C. coffeicola, e o número de lesões por folha. Após as avaliações, as plantas foram colhidas e lavadas em água desmineralizada. Após separar as raízes da parte aérea, calculou-se a porcentagem de desfolha e a área foliar total. Em seguida, as folhas, as raízes e os caules foram acon- 
dicionados separadamente em sacos de papel e secados em estufa, por três a quatro dias, a $70^{\circ} \mathrm{C}$, até atingirem peso constante. O material foi pesado, sendo determinados os teores foliares de N, K, P, S, Ca, Mg, Cu, Fe, Mn e $\mathrm{Zn}$.

Os valores da contagem do número total de folhas, do número de folhas com lesão e do número de lesões por folha foram transformados em proporções de área abaixo da curva de progresso da doença. Todos os dados foram submetidos à análise de variância e regressão.

\section{Resultados e Discussão}

\section{Peso de matéria seca, área foliar total e número total de folhas}

Com o aumento do $\mathrm{N}$, houve incremento significativo na produção de matéria total das mudas secas do cafeeiro, na área foliar total, e na área abaixo da curva de progresso do número total de folhas, e não houve influência do K sobre elas (Figura 1). Isto é, a nutrição nitrogenada nas maiores doses, sem outros fatores limitantes, é evidenciada no desenvolvimento rápido da planta, no aumento do número de ramos plagiotrópicos, na formação abundante de folhas verdes brilhantes (Malavolta et al., 1974), e, conseqüentemente, no aumento da área foliar, no número de folhas, e no peso da matéria seca total. Porém, Salazar-Arias (1977) observou efeito negativo do N no desenvolvimento e também no peso da matéria seca das mudas, o que se deveu possivelmente ao aumento da concentração de sais na solução do solo, com conseqüente elevação da pressão osmótica, que causou desidratação das plantas. Esse efeito não foi observado nas doses de $\mathrm{N}$ estudadas, que foram estabelecidas de modo a não ultrapassar os limites de pressão osmótica adequados ao nível das raízes.

$\mathrm{O} \mathrm{K}$ não teve efeito significativo, provavelmente porque o nível mínimo ( $3 \mathrm{mmol} / \mathrm{L})$ foi suficiente para nutrir as plantas. Entretanto, no campo, é possível que isso não ocorra, pois Malavolta et al. (1974) afastam a hipótese de "alimentação de luxo" do K em cafeeiros adultos e produtivos, provavelmente pelo aumento da exigência em K com a idade da planta, sendo particularmente intensa quando a planta atinge a maturidade, em virtude das quantidades extraídas pelos frutos na colheita. Além disso, o K tem efeito na formação de amido nas folhas; quando baixa o seu teor nas folhas, a produção de amido dimi-
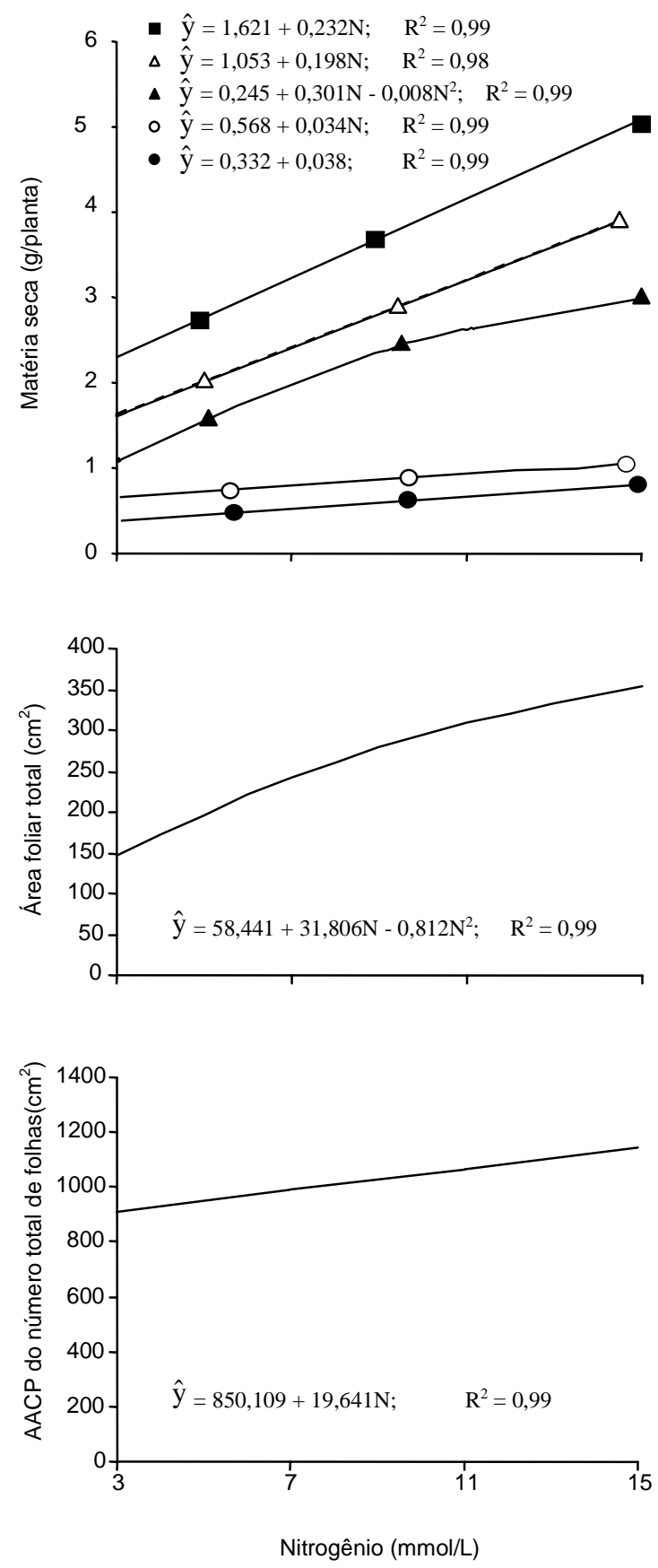

Figura 1. Produção de matéria seca total (ם), da parte aérea $(\Delta)$, da folha $(\boldsymbol{\Delta})$, da raiz $(\mathrm{O})$ e do caule $(\bullet)$, área foliar total e área abaixo da curva de progresso (AACP) do número total de folhas de mudas de cafeeiro, em razão de doses de $\mathrm{N}$, em solução nutritiva. 
nui, e, como conseqüência, a formação de novos ramos e novas folhas reduz-se, o número de grãos chochos aumenta, e a colheita diminui.

$\mathrm{O}$ aumento do $\mathrm{K}$ reduz a suscetibilidade das plantas hospedeiras a parasitas obrigatórios e facultativos; porém, na maioria dos casos, o efeito do K está restrito à faixa de deficiência. Quando o desenvolvimento é máximo e o fornecimento de K se mantém, ocorrem reduções nos níveis de outros cátions, como o Ca e o Mg, em decorrência da competição nos sítios de absorção nas raízes. Em plantas que recebem suprimento de $\mathrm{Ca}$ abaixo do ideal, o risco de desordens relacionadas ao $\mathrm{Ca}$ e a suscetibilidade das plantas a doenças tende a aumentar (Marschner, 1995).

\section{Intensidade da mancha-de-olho-pardo e da desfolha}

A área abaixo da curva de progresso do número de folhas lesionadas (AACPFL) não foi influenciada pela nutrição, indicando, assim, que, dentro dos intervalos estudados, as doses de $\mathrm{N}$ e K não interferiram significativamente na incidência da mancha-deolho-pardo.

A área abaixo da curva de progresso do número de lesões por folha (AACPLPF), e a desfolha, diminuíram com o aumento das doses de $\mathrm{N}$ e redução das doses de K, ou seja, a severidade da doença aumentou com o aumento das doses de $\mathrm{K}$ e redução das doses de N (Figuras 2 e 3 ).

A relação entre o incremento das doses de $\mathrm{N}$ e a menor severidade da mancha-de-olho-pardo em mudas de cafeeiro, assim como o efeito desfavorável do $\mathrm{K}$, ou seja, a maior severidade da doença foi obtida com a elevação das doses de K, são particularmente interessantes, pois, na literatura consultada sobre ensaios realizados com macros e micronutrientes, encontrou-se que o $\mathrm{N}$ aumenta a suscetibilidade em várias plantas. Com relação ao $\mathrm{K}$, o resultado também difere das informações disponíveis, em que este mineral aumenta a resistência das plantas às doenças. De acordo com Ito et al. (1993), por exemplo, o uso da fertilização adequada em K constituiu-se em um dos fatores que, aliado à resistência varietal, a técnicas culturais e de proteção de plantas, reduziu o nível de severidade da queima foliar da soja (C. kikuchii), embora não tenham sido observadas as relações com outros nutrientes. $\mathrm{O}$ efeito depressivo das aplicações de K além da dose ótima foi observado também por Mascarenhas et al. (1997), no cancro da haste da soja. Doses até $160 \mathrm{mg} / \mathrm{kg}$ de $\mathrm{K}_{2} \mathrm{O}$ foram efetivas na redução da doença; a partir daí, até a dose de $400 \mathrm{mg} / \mathrm{kg}$ de $\mathrm{K}_{2} \mathrm{O}$, a doença evoluiu rapidamente, aumentando a severidade. Esses autores atribuíram a evolução da doença ao desequilíbrio entre os cátions, porém não realizaram análise química foliar para verificar quais cátions estavam envolvidos no desequilíbrio.

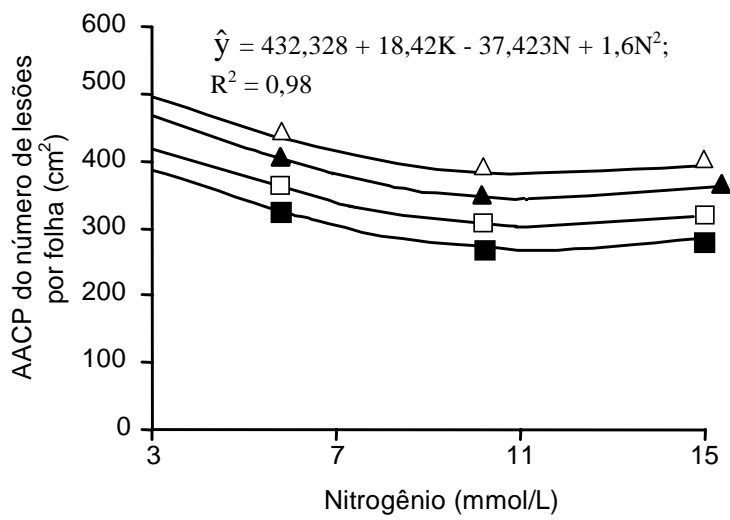

Figura 2. Área abaixo da curva de progresso (AACP) do número de lesões de Cercospora coffeicola por folha de cafeeiro, em razão de doses de $\mathrm{N}$ em cada dose de $\mathrm{K}$ (3)

$5 \square, 7 \Delta$ e $9 \Delta \mathrm{mmol} / \mathrm{L}$ ), em solução nutritiva.

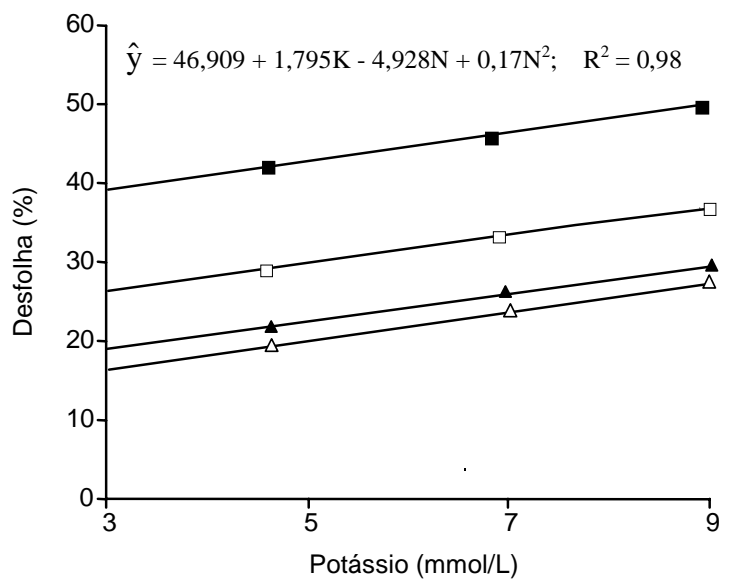

Figura 3. Porcentagem de desfolha causada por Cercospora coffeicola, em razão de doses de $\mathrm{K}$ em cada dose de $\mathrm{N}(3 \square, 7 \square, 11 \Delta$ e $15 \Delta \mathrm{mmol} / \mathrm{L})$, em solução nutritiva. 
Dados de incidência podem equivaler-se com a desfolha, em que uma ou poucas lesões causam queda de folhas na planta. Moraes et al. (1974) estudaram a influência do estado nutricional do cafeeiro na intensidade da ferrugem-do-cafeeiro $(H$. vastatrix $) \mathrm{e}$ observaram diferença significativa e positiva na porcentagem de incidência nas folhas dos tratamentos que receberam a maior dose de $\mathrm{K}$ em relação aos que não receberam este nutriente, ou seja, os tratamentos que receberam altas doses de $\mathrm{K}$ aumentaram significativamente a porcentagem de incidência de ferrugem-das-folhas, conforme observado no presente ensaio. Entretanto, Fernandes (1988) verificou a redução da desfolha por $C$. coffeicola com o aumento das doses de $\mathrm{P}$ e $\mathrm{K}$, com a mesma dose de $\mathrm{N}$.

\section{Cálcio e cobre}

Possivelmente, esses dois nutrientes foram responsáveis pelo aumento na intensidade da mancha-deolho-pardo como pode-se observar pela Figura 4. O aumento das doses de K causou redução do teor foliar de $\mathrm{Ca}$ em todas as doses de $\mathrm{N}$, sendo a dose mínima de $\mathrm{Ca}$ obtida com as doses $8,94 \mathrm{mmol} / \mathrm{L}$ de $\mathrm{K}$ e $15 \mathrm{mmol} / \mathrm{L}$ de N. Embora os teores foliares observados $(0,96$ a $1,36 \mathrm{dag} / \mathrm{kg})$ não possam ser considerados baixos, de acordo com Malavolta (1993), que indica como adequados para plantas adultas teores entre 1,0 a 1,4 dag/kg, e Rodrigues (1997), que encontrou em plantas jovens teores entre 1,1 a $1,9 \mathrm{dag} / \mathrm{kg}$, doses elevadas de $\mathrm{K}$ e N, levaram a uma concentração de Ca no limite inferior da faixa considerada como adequada. Concentrações desta ordem podem não ser limitantes ao crescimento do cafeeiro, podendo, entretanto, permitir uma maior severidade da mancha-de-olho-pardo.

Em cafeeiros formados em solo LE, Viana et al. (1986) observaram que o aumento nas doses de K causou efeito depressivo nos teores foliares de $\mathrm{Ca}$, $\mathrm{Mg}$ e B. Também em experimento com Botrytis cinerea em alface, à medida que $\mathrm{o} \mathrm{K}$ aumentou e $\mathrm{o}$ Ca diminuiu, houve elevação na incidência da doença. A soma de cátions $(\mathrm{K}+\mathrm{Ca}+\mathrm{Mg})$ foi mantida constante. Experimentos adicionais mostraram que o incremento no teor de $\mathrm{K}$ não leva a aumento da doença, desde que o Ca permaneça alto (Marchner, 1995). De acordo com Elad \& Kirshner (1992), a aplicação foliar de Ca também reduziu a severidade de B. cinerea em plantas de ruscus (Ruscus hypoglossum $\mathrm{L}$.).

Vários autores citam o Ca como redutor da severidade de doenças. Um exemplo é a redução do ataque de mofo-cinzento em roseira (Volpin \& Elad, 1991). Entretanto, não consta, na literatura, referência ao efeito do Ca sobre a mancha-de-olho-pardo do cafeeiro. A maior parte dos parasitas fúngicos invade o apoplasto, liberando enzimas pectolíticas que dissolvem a lamela média. A atividade dessas enzimas é extremamente inibida pelo $\mathrm{Ca}$, o que explica a alta correlação entre conteúdo de Ca nos tecidos e sua resistência a doenças fúngicas (Marschner, 1995). De acordo com Agrios (1988), esse nutriente reduz a severidade de várias doenças, por ser constituinte de parede celular, conferindo resistência à penetra-
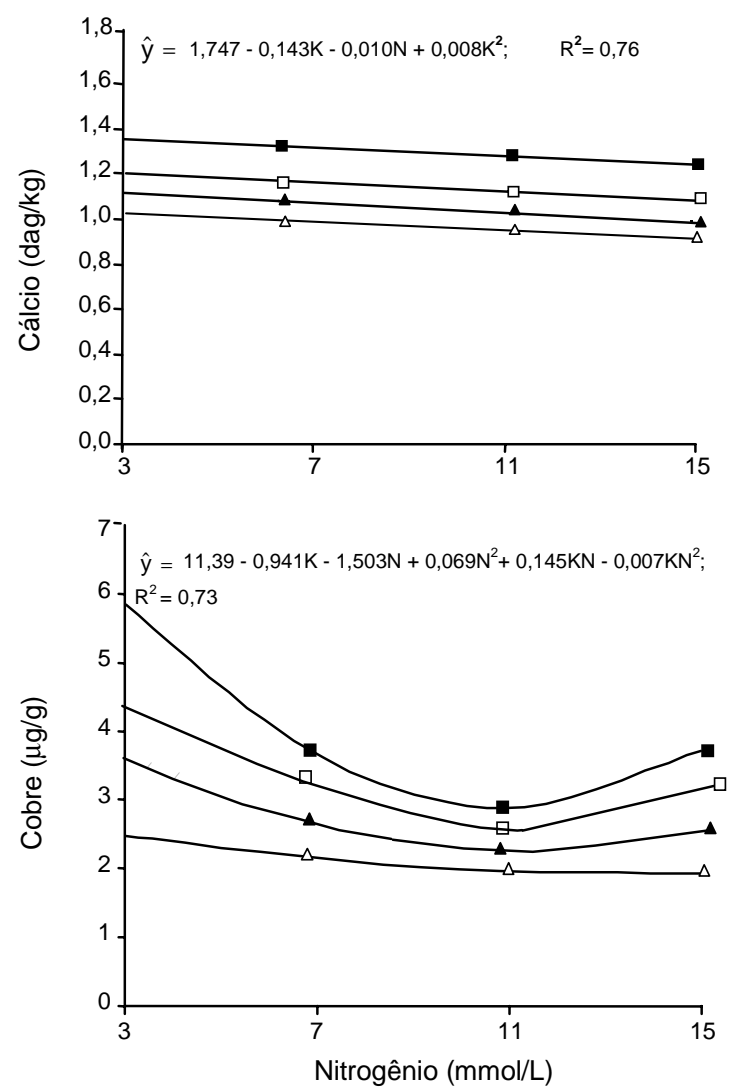

Figura 4. Teores de $\mathrm{Ca}$ e $\mathrm{Cu}$ nas folhas, em razão de doses de $\mathrm{N}$ em cada dose de $\mathrm{K}(3 \square, 5 \square, 7 \Delta$ e $9 \Delta \mathrm{mmol} / \mathrm{L})$, em solução nutritiva. 
ção do patógeno. Se a penetração de $C$. coffeicola ocorresse somente via estômatos, conforme observou Siddiqi (1969), o Ca poderia ser menos importante; entretanto, Castaño (1956) comprovou a penetração por estômatos e diretamente através da cutícula, onde o $\mathrm{Ca}$ assume grande importância, pois inibe a atividade de enzimas pectolíticas.

Quanto ao $\mathrm{Cu}$, a redução do seu teor, de 5,79 para $1,30 \mu \mathrm{g} / \mathrm{g}$ nas folhas com o aumento das doses de $\mathrm{K}$ (Figura 4). Rodrigues (1997) encontrou teores variando de 6 a $15 \mu \mathrm{g} / \mathrm{g}$ em plantas com 6,5 meses de idade, e considerou-os adequados. Provavelmente, esse foi um dos fatores responsáveis pelo aumento da doença com o aumento das doses de K, pois estudos mostram que plantas deficientes em $\mathrm{Cu}$ são mais suscetíveis à ocorrência de míldio, possivelmente por inibição da lignificação, redução no metabolismo de fenóis (supressão), acúmulo de carboidratos solúveis, e senescência foliar precoce (Marschner, 1995). Além disso, o $\mathrm{Cu}$ é utilizado como um fungicida eficiente para o controle da mancha-de-olho-pardo, em quantidades superiores à exigência nutricional do cafeeiro (Pozza et al., 1997).

\section{Fósforo e magnésio}

Os teores foliares de $\mathrm{P}$ e de $\mathrm{Mg}$ apresentaram comportamento semelhante. Houve queda nas concentrações com o aumento das doses de $\mathrm{N}$, até $10,9 \mathrm{mmol} / \mathrm{L}$ em relação ao $\mathrm{P}$, e até $12 \mathrm{mmol} / \mathrm{L}$ em relação ao $\mathrm{Mg}$. Em seguida, verificou-se pequeno aumento das concentrações foliares desses nutrientes (Figura 5). É provável que esse comportamento se deva a um efeito de diluição, uma vez que as plantas responderam ao $\mathrm{N}$ com incremento na produção de matéria das mudas secas. De todo modo, observa-se que os teores foliares, variando de 0,26 a $0,29 \mathrm{dag} / \mathrm{kg}$ para $\mathrm{P}$ e de 0,27 a $0,36 \mathrm{dag} / \mathrm{kg}$ para $\mathrm{Mg}$, situam-se na faixa de concentrações considerada adequada para o cafeeiro por Malavolta (1993). Rodrigues (1997) e Braccini (1995) obtiveram teores foliares de $\mathrm{P}$ variando entre 0,16 a $0,27 \mathrm{dag} / \mathrm{kg}$, e de $\mathrm{Mg}$ entre 0,27 a 0,38 dag/kg em plantas jovens de café com nutrição adequada.

A combinação do $\mathrm{P}$ com o $\mathrm{K}$ em doses crescentes, para uma mesma dose de $\mathrm{N}$, foi importante para a redução da mancha-de-olho-pardo em cafeeiro, em trabalho realizado por Fernandes (1988), porém não
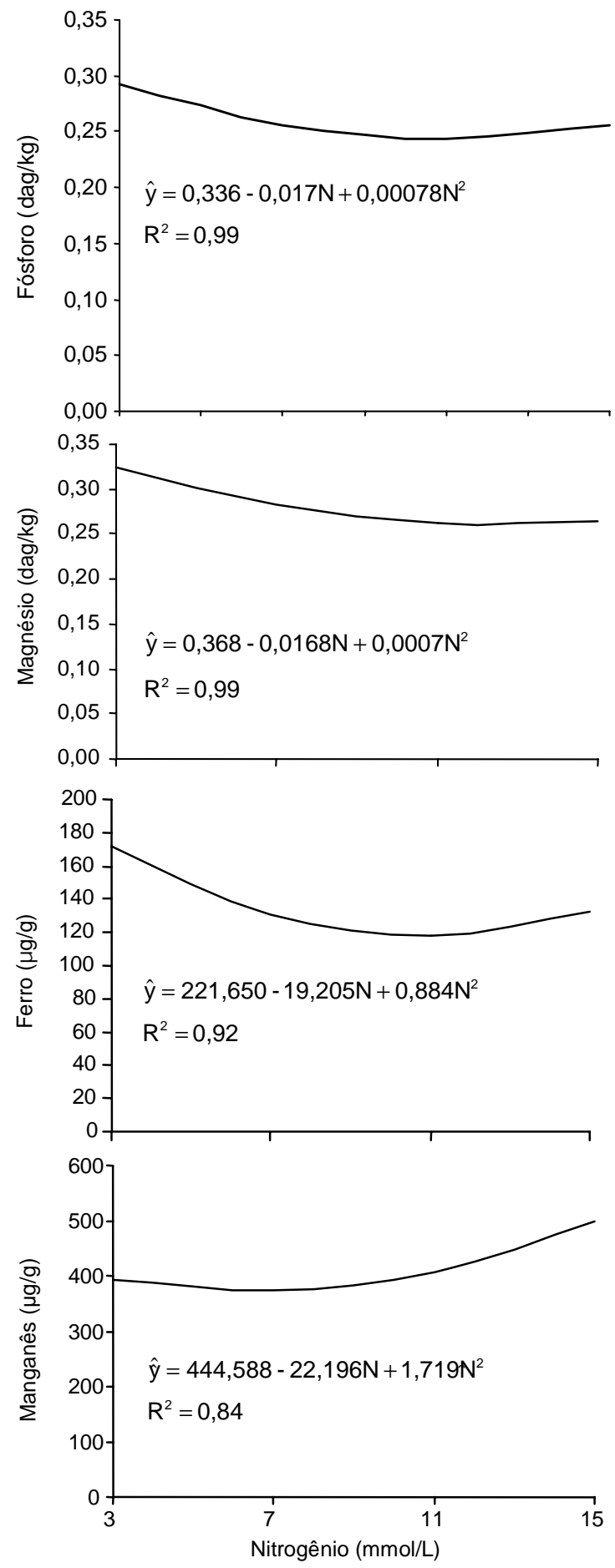

Figura 5. Teores de $\mathrm{P}, \mathrm{Mg}, \mathrm{Fe}$ e $\mathrm{Mn}$ nas folhas, em razão de doses de $\mathrm{N}$, em solução nutritiva. 
se observou a relação do $\mathrm{P}$ com o K no presente trabalho.

\section{Ferro e manganês}

Da mesma forma que o Mn, com o aumento das doses de $\mathrm{N}$ até $10,8 \mathrm{mmol} / \mathrm{L}$, os teores foliares de $\mathrm{Fe}$ sofreram pequena redução, elevando-se a seguir ( $\mathrm{Fi}$ gura 5). Rodrigues (1997) encontrou concentrações de 70 a $200 \mu \mathrm{g} / \mathrm{g}$ em plantas de café com 6,5 meses de idade, e considerou-as adequadas ao desenvolvimento. Neste experimento foram constatados teores de Fe entre 138,47 a $172 \mu \mathrm{g} / \mathrm{g}$, e Malavolta (1993) considera adequados teores de 90 a $180 \mu \mathrm{g} / \mathrm{g}$ em plantas adultas e produtivas. De acordo com Zambolim \& Ventura (1996), estudos sobre o hospedeiro sugerem que o íon Fe pode atuar na ativação de enzimas necessárias para a síntese de compostos antifúngicos. A ausência do íon Fe resulta na suscetibilidade das células, pela ausência da produção de compostos antifúngicos. Porém a deficiência desse nutriente não foi detectada no presente experimento.

Com o aumento das doses de $\mathrm{N}$ até $6,45 \mathrm{mmol} / \mathrm{L}$, os teores foliares de $\mathrm{Mn}$ sofreram pequena redução, elevando-se a seguir (Figura 5). A faixa de concentrações encontrada por Rodrigues (1997) é de 50 a $150 \mathrm{mg} / \mathrm{g}$ para plantas de café com 6,5 meses de idade. Conforme resultados obtidos no presente experimento, foram constatados teores de Mn entre 393,48 a 498,42 $\mu \mathrm{g} / \mathrm{g}$, e Malavolta (1993) considera excessivos teores maiores que $300 \mu \mathrm{g} / \mathrm{g}$. As altas concentrações de Mn são devidas provavelmente à presença do elemento como contaminante na areia, apesar da lavagem ácida, porém não foram observadas alterações no desenvolvimento da planta nestas concentrações. Alta concentração de Mn inibe, por competição, a absorção de $\mathrm{Fe}$ e a sua translocação, pois este nutriente é responsável pela ativação de enzimas envolvidas na redução do nitrato, no metabolismo de carboidratos, e na respiração (Huber, 1980). Entretanto, isso não foi verificado no experimento, uma vez que os teores de Fe encontram-se nos níveis considerados adequados.

\section{Zinco}

$\mathrm{O}$ teor de $\mathrm{Zn}$ nas folhas foi significativamente influenciado por K, e não foi afetado por N. A Figura 6 representa a redução linear no teor de $\mathrm{Zn}$ com o aumento das doses de $\mathrm{K}$, variando de 66,88 a $19,42 \mu \mathrm{g} / \mathrm{g}$. Rodrigues (1997) observou teores de 5 a $20 \mu \mathrm{g} / \mathrm{g}$ e considerou-os adequados ao desenvolvimento de cafeeiros com 6,5 meses de idade. As altas concentrações de $\mathrm{Zn}$ são devidas provavelmente à presença do elemento como contaminante na areia, apesar da lavagem ácida, porém não foram observadas alterações no desenvolvimento da planta nessas concentrações. É possível que a acentuada redução no teor foliar de $\mathrm{Zn}$ com o aumento do K na solução nutritiva tenha ocorrido por competição entre cátions, e o menor nível de $\mathrm{Zn}$ encontra-se na faixa considerada adequada. Há relatos de que o $\mathrm{Zn}$ contribui para a resistência da planta ao ataque de patógenos. Em algodão, por exemplo, plantas crescendo em solo com aplicação de $100 \mu \mathrm{g} / \mathrm{g}$ de $\mathrm{Zn}$ mostram resistência ao Fusarium oxysporum f. sp. vasinfectum. O papel do Zn, nesse caso, é aumentar o conteúdo de ácido ascórbico e carboidratos das plantas, conferindo, desta forma, resistência (Zambolim \& Ventura, 1996). Em seringueira deficiente em Zn, há perda de açúcares nas superfícies radiculares, com aumento da infecção por oídio (Marschner, 1995). O mesmo ocorre com a mancha-de-olho-pardo do cafeeiro, mas o modo de ação do Zn em relação a esta ainda não está completamente esclarecido.

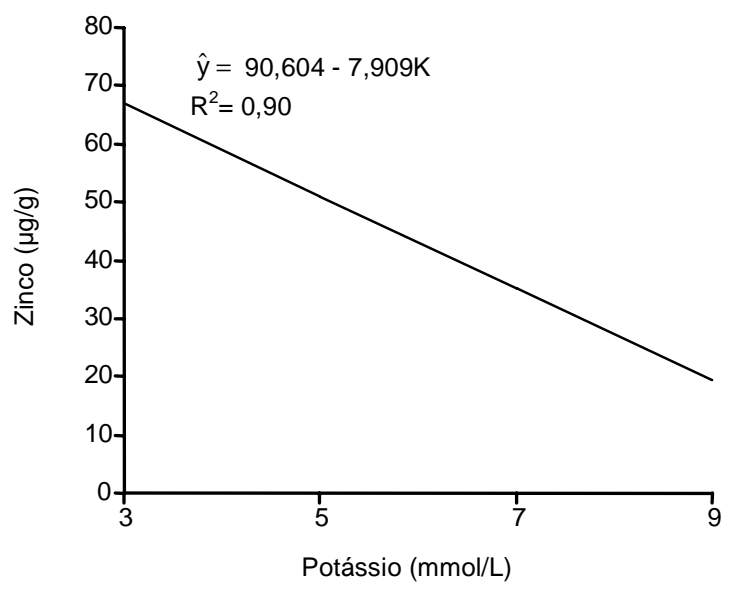

Figura 6. Teor de $\mathrm{Zn}$ nas folhas, em razão de doses de K, em solução nutritiva. 


\section{Conclusões}

1. O aumento da nutrição nitrogenada controla a mancha-de-olho-pardo, e o aumento da nutrição potássica causa aumento indireto da doença.

2. A porcentagem de desfolha é uma medida que equivale à incidência da doença.

3. Doses excessivas de potássio em viveiro favorecem a doença e prejudicam a muda.

4. A nutrição nitrogenada reduz, mas não impede a incidência da mancha-de-olho-pardo em mudas de café.

\section{Agradecimentos}

À FAPEMIG e à CAPES, pelo apoio financeiro para a realização do experimento.

\section{Referências}

AGRIOS, G. M. Plant pathology. 3. ed. London : Academic, 1988. 803 p.

BRACCINI, M. do C. L. Comportamento de nove populações de café quanto à tolerância ao alumínio em solução nutritiva. Viçosa : UFV, 1995. 92 p. Dissertação de Mestrado.

CASTAÑO, J. J. Mancha de hierro del cafeto. Cenicafe, Chinchina, v. 7, n. 4, p. 313-327, 1956.

ELAD, Y.; KIRSHNER, B. Calcium reduces Botrytis cinerea damages to plants of Ruscus hypoglossum. Phytoparasitica, Rehovot, v. 20, n. 4, p. 285-291, 1992.

FERNANDES, C. D. Efeito de fatores do ambiente e da concentração de inóculo sobre a cercosporiose do cafeeiro. Viçosa : UFV, 1988. 73 p. Dissertação de Mestrado.

FERNANDEZ-BORRERO, O.; MESTRE, A. M.; DUQUE, S. I. L. Efecto de la fertilización en la incidencia de la mancha de hierro (Cercospora coffeicola) en frutos de café. Cenicafe, Chinchina, v. 17, n. 1, p. 5-6, 1966.

HOAGLAND, D. R.; ARNON, D. I. The water-culture method for growing plants without soil. Berkeley : University of California at Berkeley, 1950. 32 p.

HUBER, D. M. The role of mineral nutrition in defense. In: HORSFAll, J. G.; COWLING, E. B. (Ed.). Plant pathology: an advanced treatise. New York : Academic, 1980. v. 5, p. 381-406.

ITO, M. F.; TANAKA, M. A. S.; MASCARENHAS, H. A. A. Efeito residual da calagem e da adubação potássica sobre a queima foliar (Cercospora kikuchii) da soja. Summa Phytopathologica, Jaboticabal, v. 19, n. 1, p. 21-23, 1993.

MALAVOLTA, E. Nutrição mineral e adubação do cafeeiro: colheitas máximas econômicas. São Paulo : Agronômica Ceres, 1993. 210 p.

MALAVOLTA, E.; HAAG; H. P.; MELLO, F. A. P. Nutrição mineral e adubação de plantas cultivadas. São Paulo : Pioneira, 1974. 727 p.

MARSCHNER, H. Mineral nutrition of higher plants. 2. ed. New York : Academic, 1995. 889 p.

MASCARENHAS, H. A. A.; ITO, M. F.; TANAKA, M. A. de S. Efeito da adubação potássica no cancro da haste da soja. Summa Phytopathologica, Jaboticabal, v. 23, n. 3/4, p. 217-221, 1997.

MORAES, F. R. P.; CERVELINI, G. S.; GALLO, J. R. Influência do estado nutricional do cafeeiro sobre a intensidade do ataque da ferrugem (Hemileia vastatrix, Berk. \& Br.). In: CONGRESSO BRASILEIRO DE PESQUISA CAFEEIRA, 2. , 1974, Poços de Caldas. [Anais]. Rio de Janeiro : IBC-GERCA, [1974]. p. 126-127.

POZZA, A. A. A.; ZAMBOLIM, L.; POZZA, E. A. Controle químico da mancha-de-olho-pardo (Cercospora coffeicola) do cafeeiro em condições de viveiro. Fitopatologia Brasileira, Brasília, v. 22, n. 4, p. 543-545, 1997.

RODRIGUES, L. A. Crescimento e composição mineral na arte aérea e nas raízes de duas variedades de café em resposta à calagem na subsuperfície do solo. Viçosa : UFV, 1997. 89 p. Dissertação de Mestrado.

SALAZAR-ARIAS, N. Respuesta de plántulas de café a la fertilización con nitrógeno, fósforo y potasio. Cenicafe, Chinchina, v. 28, n. 2, p. 61-66, 1977.

SIDDIQI, M. A. Incidence, development and symptoms of Cercospora disease of coffee in Malawi. British Mycological Society Transactions, Cambridge, Grã-Bretanha, v. 54, n. 3, p. 415-421, 1969.

VIANA, A. S.; GARCIA, A. W. R.; CORRÊA, J. B. Estudo de níveis e relações N/K na formação de cafeeiros em solo LE-III. In: CONGRESSO BRASILEIRO DE PESQUISA CAFEEIRA, 13. , 1986, São Lourenço. Anais... Rio de Janeiro : Ministério da Agricultura, [1986]. p. 6871.

VOLPIN, H.; ELAD, Y. Influence of calcium nutrition on susceptibility of rose flowers to gray mold. Phytopathology, St. Paul, v. 81, n. 1, p. 1390-1394, 1991.

ZAMBOLIM, L.; VENTURA, J. A. Resistência a doenças induzidas pela nutrição das plantas. Piracicaba : POTAFOS, 1996. 16 p. (Encarte Técnico. Informações Agronômicas, 75). 